NASA/TM-2003-212288

\title{
Optimal Disturbances in Boundary Layers Subject to Streamwise Pressure Gradient
}

\author{
Anatoli Tumin \\ University of Arizona, Tucson, Arizona \\ David E. Ashpis \\ Glenn Research Center, Cleveland, Ohio
}


Since its founding, NASA has been dedicated to the advancement of aeronautics and space science. The NASA Scientific and Technical Information (STI) Program Office plays a key part in helping NASA maintain this important role.

The NASA STI Program Office is operated by Langley Research Center, the Lead Center for NASA's scientific and technical information. The NASA STI Program Office provides access to the NASA STI Database, the largest collection of aeronautical and space science STI in the world. The Program Office is also NASA's institutional mechanism for disseminating the results of its research and development activities. These results are published by NASA in the NASA STI Report Series, which includes the following report types:

- $\quad$ TECHNICAL PUBLICATION. Reports of completed research or a major significant phase of research that present the results of NASA programs and include extensive data or theoretical analysis. Includes compilations of significant scientific and technical data and information deemed to be of continuing reference value. NASA's counterpart of peerreviewed formal professional papers but has less stringent limitations on manuscript length and extent of graphic presentations.

- TECHNICAL MEMORANDUM. Scientific and technical findings that are preliminary or of specialized interest, e.g., quick release reports, working papers, and bibliographies that contain minimal annotation. Does not contain extensive analysis.

- CONTRACTOR REPORT. Scientific and technical findings by NASA-sponsored contractors and grantees.
- CONFERENCE PUBLICATION. Collected papers from scientific and technical conferences, symposia, seminars, or other meetings sponsored or cosponsored by NASA.

- SPECIAL PUBLICATION. Scientific, technical, or historical information from NASA programs, projects, and missions, often concerned with subjects having substantial public interest.

- TECHNICAL TRANSLATION. Englishlanguage translations of foreign scientific and technical material pertinent to NASA's mission.

Specialized services that complement the STI Program Office's diverse offerings include creating custom thesauri, building customized databases, organizing and publishing research results ... even providing videos.

For more information about the NASA STI Program Office, see the following:

- Access the NASA STI Program Home Page at http://www.sti.nasa.gov

- E-mail your question via the Internet to help@sti.nasa.gov

- Fax your question to the NASA Access Help Desk at 301-621-0134

- Telephone the NASA Access Help Desk at 301-621-0390

- Write to:

NASA Access Help Desk

NASA Center for AeroSpace Information 7121 Standard Drive

Hanover, MD 21076 
NASA/TM-2003-212288

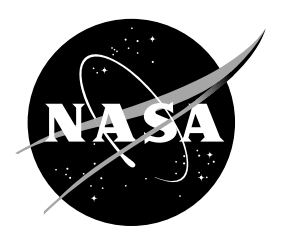

\title{
Optimal Disturbances in Boundary Layers Subject to Streamwise Pressure Gradient
}

\author{
Anatoli Tumin \\ University of Arizona, Tucson, Arizona \\ David E. Ashpis \\ Glenn Research Center, Cleveland, Ohio
}

Prepared for the

16th Computational Fluid Dynamics Conference and the 33rd Fluid Dynamics Conference and Exhibit

sponsored by the American Institute of Aeronautics and Astronautics

Orlando, Florida, June 23-26, 2003

National Aeronautics and

Space Administration

Glenn Research Center 


\section{Acknowledgments}

The first author was partially supported by an AFOSR grant monitored by Dr. J. Schmisseur and partially by NASA Glenn Research Center under Cooperative Agreement NCC3-991. The authors appreciate useful comments provided by Dr. Stuart Leib of the Ohio Aerospace Institute.

Trade names or manufacturers' names are used in this report for identification only. This usage does not constitute an official endorsement, either expressed or implied, by the National Aeronautics and Space Administration.

Available from

NASA Center for Aerospace Information 7121 Standard Drive

Hanover, MD 21076
National Technical Information Service 5285 Port Royal Road Springfield, VA 22100 


\title{
OPTIMAL DISTURBANCES IN BOUNDARY LAYERS SUBJECT TO STREAMWISE PRESSURE GRADIENT
}

\author{
Anatoli Tumin ${ }^{*}$ \\ The University of Arizona \\ Tucson, Arizona 85721 \\ David E. Ashpis ${ }^{\dagger}$ \\ National Aeronautics and Space Administration \\ Glenn Research Center \\ Cleveland, Ohio 44135
}

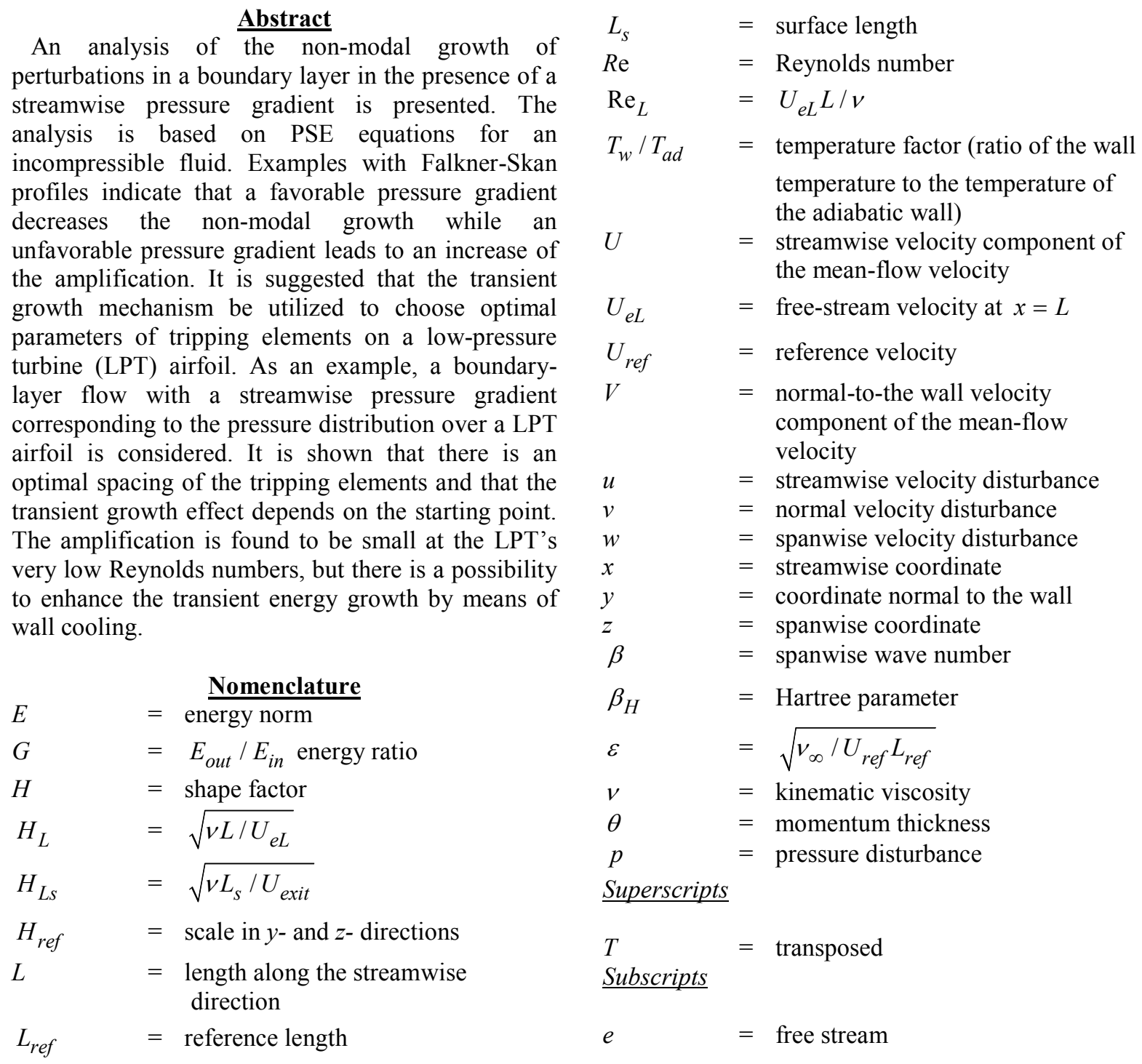

\footnotetext{
*Assistant Professor, Department of Aerospace and Mechanical Engineering. Senior Member AIAA, tumin@engr.arizona.edu.

${ }^{\dagger}$ Aerospace Engineer. Senior Member AIAA, ashpis@nasa.gov
} 


$$
\begin{array}{ll}
\text { exit } & =\text { exit conditions } \\
\text { in } & =\text { starting point } \\
\text { out } & =\text { ending point }
\end{array}
$$

\section{Introduction}

Laminar-turbulent transition in shear flows is still an enigma in the area of fluid mechanics. The conventional explanation of the phenomenon is based on the instability of the shear flow with respect to infinitesimal disturbances. The conventional hydrodynamic stability theory deals with the analysis of normal modes that might be unstable. The latter circumstance is accompanied by an exponential growth of the disturbances that might lead to laminarturbulent transition. Nevertheless, in many cases, the transition scenario bypasses the stage of the exponential growth associated with the normal modes. This type of transition is called bypass transition. Observations of laminar-turbulent transition in plane Couette flow, in circular pipe flow, in boundary layers at relatively low Reynolds numbers, etc., can serve as examples of bypass transition. An understanding of the phenomenon has eluded us to this day. One possibility is that bypass transition is associated with so-called algebraic growth of disturbances in shear flows ${ }^{1-3}$.

The phenomenon of algebraic growth of disturbances in shear flows has been of great interest during the last two decades as it may be associated with the bypass transition mechanism. Ellingsen and Palm ${ }^{1}$ considered, in the inviscid case, an initial disturbance independent of the streamwise coordinate and found that the streamwise disturbance amplitude may grow in time, even though the basic flow does not posses an inflection point. Landahl ${ }^{2}$ showed that all parallel inviscid shear flows are unstable to a wide class of three-dimensional disturbances. The result is independent of whether or not the shear flow is unstable to an exponential growth of wavelike disturbances. This type of instability that is not related to exponential growth is also referred to as "non-modal growth." Mathematically, the effect of non-modal growth is associated with non-normality of the linearized Navier-Stokes operator and nonorthogonality of the eigenfunctions. In simple words, the essence of non-modal growth is the possibility of combining the exponentially decaying modes in such way that their sum will possess transient growth. One can find a vast bibliography on the topic in the Otto Laporte Award Lecture by Reshotko ${ }^{3}$ and in a monograph by Schmid and Henningson. ${ }^{4}$

Numerical analysis of spatial non-modal growth within the scope of the linearized boundary-layer equations for an incompressible flow over a flat plate was carried out in Refs. 5 and 6. Spatial analysis within the scope of the linearized Navier-Stokes equations (quasi-parallel approximation of compressible and incompressible flows) was presented in Refs. 7 to 9. The main results of these theoretical models are as follows:

- A system of counter-rotating streamwise vortices, which are periodic in the spanwise direction, provides the strongest growth of the disturbance.

- There is an optimal spacing of the streamwise vortices, leading to the strongest effect.

The effect of pressure gradients on the transient growth mechanism was considered within the scope of temporal theory by Corbett and Bottaro ${ }^{10}$ and within the scope of spatial theory by Tumin and Reshotko. ${ }^{9}$ These results were based on the quasiparallel flow assumption. Tumin ${ }^{11}$ analyzed the pressure gradient effect for the Falkner-Skan profile within the scope of an analytical model when the spanwise wave number is very small. The pressuregradient effect within the scope of spatial theory with nonparallel base flow and finite spanwise wave numbers has not been considered, yet.

Another motivation for the present work stems from separation flow control on low-pressure turbines (LPT). The performance of LPTs is strongly affected by the flow separation. There is a possibility of delaying the boundary-layer separation by tripping the boundary layer with the help of roughness elements or other devices. Usually, trial-and-error method is used to determine an appropriate placement of the control elements. This approach is time consuming and expensive. A recent investigation by Reshotko and Tumin ${ }^{12}$ demonstrated that roughness-induced transition might be related to the transient growth mechanism.

Periodically spaced in the spanwise direction, roughness elements generate a system of counterrotating streamwise vortices. Due to a secondary instability mechanism, the streamwise vortices can lead to earlier transition to turbulence. They also provide a mixing enhancement due to redistribution of the streamwise momentum. Consequently, optimization of the streamwise vortices for maximum energy growth leads to maximizing of the flow control effectiveness. In the present work, analysis of the optimal disturbances/streamwise vortices associated with the transient growth mechanism will be performed for boundary layers in the presence of a streamwise pressure gradient. The theory will provide 
the optimal spacing of the control elements in the spanwise direction and their placement in the streamwise direction.

\section{Governing Equations}

Because the flows of interest have relatively low Mach numbers, we consider steady three-dimensional disturbances in an incompressible two-dimensional boundary layer. We choose the streamwise coordinate $x$ along the surface. The coordinate $y$ will measure distance from the wall. We define a small parameter $\varepsilon=\sqrt{v / U_{\text {ref }} L_{r e f}}$, where $v, U_{\text {ref }}$, and $L_{\text {ref }}$ are viscosity, reference velocity, and reference length, respectively. The streamwise coordinate is scaled with $L_{r e f}$ while the vertical coordinate $y$ and spanwise coordinate $z$ are scaled with $\sqrt{v L_{r e f} / U_{r e f}}$. The following scaling is assumed for the velocity disturbances $u, v$, and $w$, and the pressure $p$ :

$$
\begin{aligned}
& u \sim U_{\text {ref }}, \quad v \sim \varepsilon U_{r e f}, \\
& w \sim \varepsilon U_{r e f}, \quad p \sim \varepsilon^{2} \rho U_{r e f}^{2}
\end{aligned}
$$

This scaling of the linearized Navier-Stokes equations and neglecting of the curvature effects lead to the governing equations for Görtler instability with the Görtler number equal to zero. We look for a periodic solution in the spanwise direction with the corresponding wave number $\beta$. The governing equations for the amplitude functions can be written in dimensionless form as follows: ${ }^{5,6}$

$$
\begin{gathered}
\frac{\partial u}{\partial x}+\frac{\partial v}{\partial y}+\beta w=0 \\
\frac{\partial}{\partial x}(U u)+V \frac{\partial u}{\partial y}+v \frac{\partial U}{\partial y}=\frac{\partial^{2} u}{\partial y^{2}}-\beta^{2} u \\
\frac{\partial}{\partial x}(u V+v U)+\frac{\partial}{\partial y}(2 V v)+ \\
\beta V w+\frac{\partial p}{\partial y}=\frac{\partial^{2} v}{\partial y^{2}}-\beta^{2} v \\
\frac{\partial}{\partial x}(U w)+\frac{\partial}{\partial y}(V w)-\beta p=\frac{\partial^{2} w}{\partial y^{2}}-\beta^{2} w
\end{gathered}
$$

where $U(x, y)$ and $V(x, y)$ are the streamwise and normal velocity components of the base flow, respectively (in addition, the latter is divided by $\varepsilon$ ). The following boundary conditions are applied to the solutions:

$$
\begin{array}{ll}
y=0: & u=v=w=0 \\
y \rightarrow \infty: & u, w, p \rightarrow 0
\end{array}
$$

The equations (2) to (5) can be solved subject to boundary conditions (6a) and (6b) with prescribed initial velocity perturbations at $x=x_{0}$. follows:

The governing equations can be recast as

$$
(\mathbf{A f})_{x}=\mathbf{B}_{0} \mathbf{f}+\mathbf{B}_{1} \mathbf{f}_{y}+\mathbf{B}_{2} \mathbf{f}_{y y}
$$

where $\mathbf{A}, \mathbf{B}_{0}, \mathbf{B}_{1}$, and $\mathbf{B}_{2}$ are $4 \times 4$ matrices (one can find them in the Appendix; see also Ref. 5) and $\mathbf{f}=(u, v, w, p)^{T}$. The superscript “ $T$ ” stands for "transposed," and the subscripts " $x$ " and " $y$ " denote differentiation with respect to $x$ and $y$, respectively.

\section{Optimization of Energy Growth}

The authors of Refs. 5 and 6 employed an iterative procedure to find the optimal disturbances in terms of the maximum of the energy growth ratio $G=E_{\text {out }} / E_{\text {in }}$, where $E_{\text {in }}$ and $E_{\text {out }}$ stand for the input and output energy norms. Andersson et al. ${ }^{5}$ used the same definitions of $E_{\text {in }}$ and $E_{\text {out }}$ as for the disturbance energy

$$
E=\int_{0}^{y_{\max }}\left(u^{2}+\varepsilon^{2} v^{2}+\varepsilon^{2} w^{2}\right) d y
$$

whereas Luchini ${ }^{6}$ employed the knowledge that the optimal disturbances are represented by streamwise vortices with corresponding output as the streamwise velocity streaks,

$$
\begin{gathered}
E_{\text {in }}=\varepsilon^{2} \int_{0}^{y_{\max }}\left(v^{2}+w^{2}\right) d y \\
E_{\text {out }}=\int_{0}^{y_{\max }} u^{2} d y
\end{gathered}
$$




$$
G=\frac{E_{\text {out }}}{E_{\text {in }}}=\varepsilon^{-2} \frac{\int_{0}^{y_{\max }} u^{2} d y}{\int_{0}^{y_{\max }}\left(v^{2}+w^{2}\right) d y}
$$

As was shown in Ref. 5, the two definitions of the optimal disturbances lead to the same results at Reynolds numbers of $10^{4}$ and higher. Because the iteration procedure based on the optimization of ratio (9c) provides significant simplification, we adopt it for the following analysis. Because Eqs. (2) to (5) are independent of $\varepsilon$, the value of $\varepsilon^{2} G$ is invariant with respect to the Reynolds number.

\section{$\underline{\text { Numerical results }}$}

\section{Falkner-Skan Base Flow}

We consider a Falkner-Skan family of boundarylayer profiles with free-stream velocity distribution $U_{e}=C x^{m}$ and corresponding Hartree parameter $\beta_{H}=2 m /(m+1)$. For convenience, we have used the velocity scale $U_{\text {ref }}=U_{e L}=C L^{m}$ and the length scale $L_{r e f}=L /(m+1)$. The latter allowed the use of the conventional scaling of boundary-layer solutions with $H_{r e f}=\sqrt{v L /(m+1) U_{e L}}=\sqrt{v L_{r e f} / U_{r e f}}$.

Figure 1 shows the scaled energy ratio versus spanwise wave number $\beta$ for three Hartree parameters, $\beta_{H}=-0.1,0.0$, and 0.1 . The starting and the ending points, $x_{i n} / L$ and $x_{\text {out }} / L$, are equal to

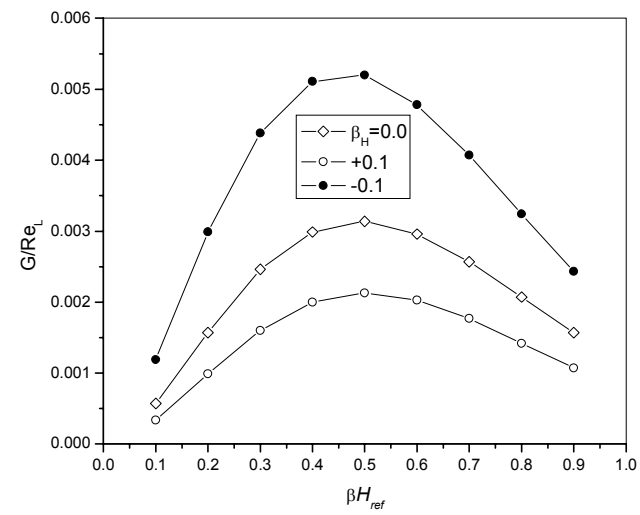

Figure 1. Effects of the spanwise wave number $\beta$ and the Hartree parameter $\beta_{H}$ on transient growth (starting point $x_{i n} / L=0.2$ ).
0.2 and 1.0, respectively. The Reynolds number $\operatorname{Re}_{L}$ in Fig. 1 and what follows is defined as $U_{e L} L / v$. One can see that an unfavorable pressure gradient $\left(\beta_{H}<0\right)$ leads to an increase in the energy growth while a favorable pressure gradient $\left(\beta_{H}>0\right)$ leads to suppression of the transient growth mechanism. The latter is consistent with results obtained within the scope of parallel flow approximation. ${ }^{5}$

Figures 2 and 3 show similar results, but the starting points are $x_{i n} / L=0.4$ and 0.6 , respectively. A comparison of Figs. 1 to 3 indicates that there is a spanwise wave number, $\beta H_{\text {ref }}=0.5-0.6$, and a starting point, $x_{i n} / L$, that maximize the energy growth. These parameters correspond to optimal spanwise spacing and streamwise placing of perturbators for maximum flow control effectiveness. Figure 4 demonstrates the energy ratio versus the downstream coordinate $x / L$ at $\beta H_{\text {ref }}=0.5$ and $x_{\text {in }} / L=0.2$.

\section{Example of LPT Conditions}

Volino $^{13}$ simulated low-pressure turbine (LPT) airfoil conditions in a low-speed wind tunnel. The test section was designed as a passage between two airfoils. The local free-stream velocity at the favorable pressure-gradient region was closely approximated by the following equation:

$$
\frac{U_{e}}{U_{\text {exit }}}=1.48\left(\frac{x}{L_{S}}\right)^{0.214}
$$

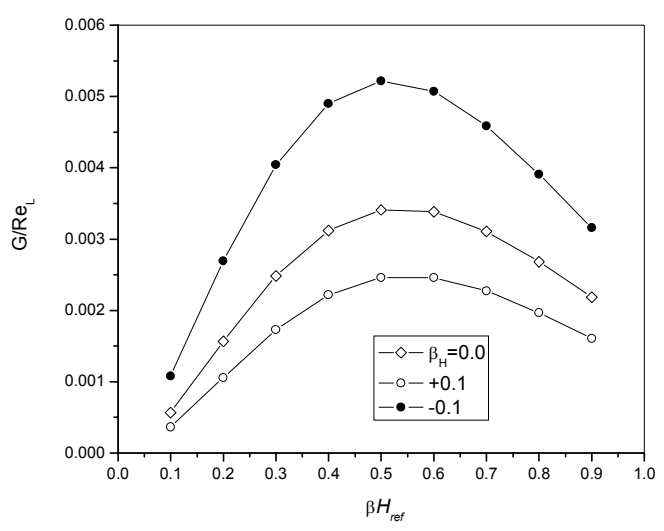

Figure 2. The same as Fig. 1, with starting point $x_{\text {in }} / L=0.4$. 


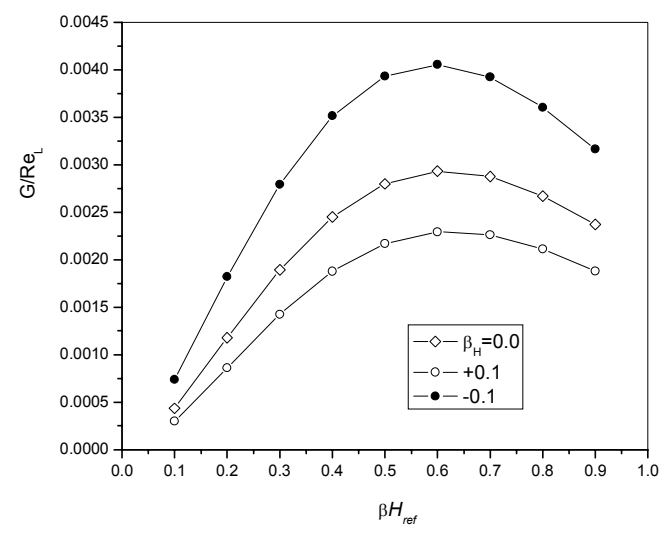

Figure 3. The same as Fig. 1, with starting point $x_{\text {in }} / L=0.6$.

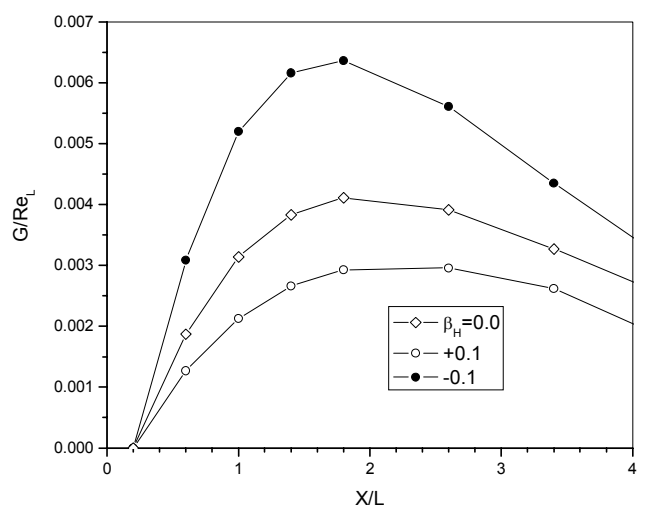

Figure 4. Optimal energy ratio versus the downstream coordinate at three Hartree parameters $\left(x_{i n} / L=0.2, \beta H_{L}=0.5\right)$.

where $L_{S}$ is the suction surface length and $U_{\text {exit }}$ is the nominal exit free-stream velocity based on the inviscid solution. The distribution (10) corresponds to the Falkner-Skan flow with the Hartree parameter $\beta_{H}=0.353$.

Figure 5 demonstrates the energy ratio scaled with the Reynolds number $\operatorname{Re}_{\text {exit }}=U_{\text {exit }} L_{s} / v$ versus the spanwise wave number scaled with $H_{L s}=\sqrt{v L_{s} / U_{\text {exit }}}$. The ending point was prescribed at $x_{\text {out }} / L_{S}=0.444$ while the starting points varied from 0.111 to 0.289 . The streamwise velocity perturbation at $x_{\text {out }} / L_{S}=0.444, x_{i n} / L_{S}=0.111$, and $\beta H_{L s}=0.925$ is shown in Fig. 6, and the corresponding optimal profiles of $v$ and $w$ are presented in Fig. 7.

The results indicate that we are dealing with a very strong favorable pressure gradient that

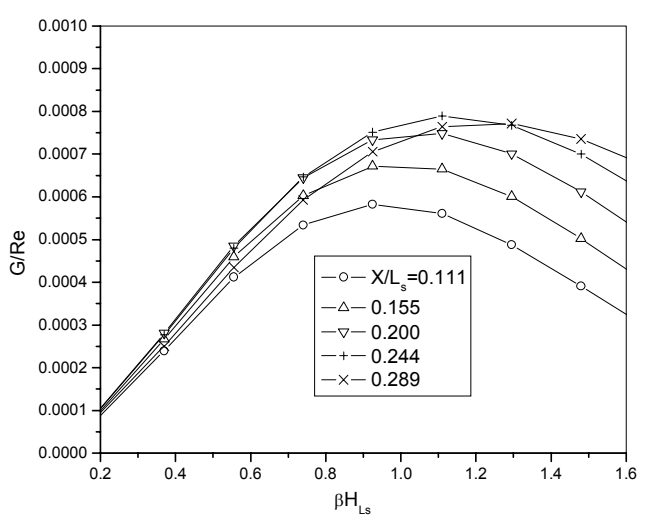

Figure 5. Effects of the spanwise wave number $\beta$ and the starting point $x_{i n} / L$ on transient growth at conditions of the experiment in Ref. $13\left(\beta_{H}=0.353\right.$, $\left.x_{\text {out }} / L_{S}=0.444\right)$.

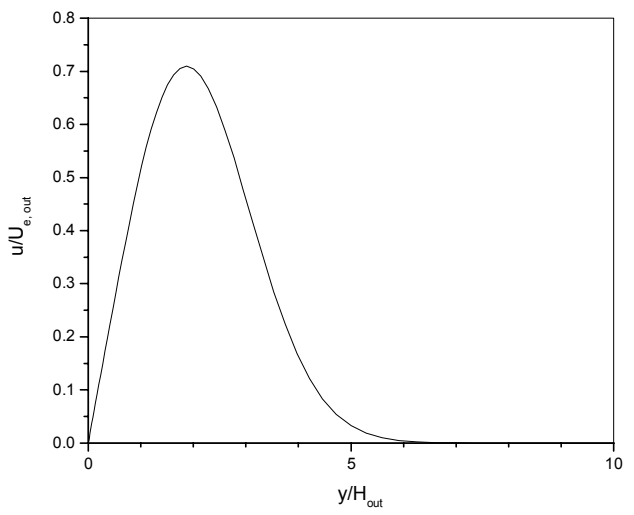

Figure 6 The streamwise velocity perturbation at the ending point $x_{\text {out }} / L_{S}=0.444$. The parameters correspond to the experimental conditions in Ref. 13 $\left(x_{i n} / L_{S}=0.111, \beta H_{L s}=0.925\right)$.

suppresses the transient growth mechanism. For an example of a typical LPT cruise Reynolds number of 50,000 , the transient growth will provide an energy amplification of less than 50. This is a relatively small number. If we take into account that in practice the perturber will not produce the optimal inflow field, the real amplification will be even of a smaller value. For example, in Blasius boundary layer, the theory predicts amplification of 250 at the same Reynolds number of 50,000 (Ref. 9). Correlation between the transient growth factor and transition has not been established yet; therefore the effectiveness of the transient growth mechanism in preventing flow separation cannot be assessed quantitatively currently. 


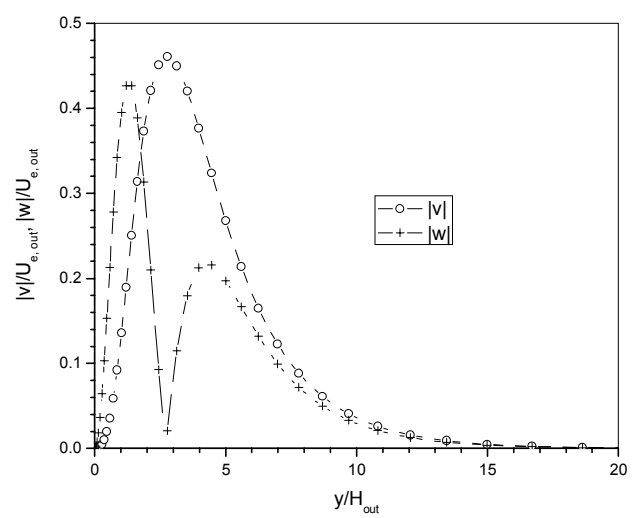

Figure 7. The optimal velocity perturbations at $x_{i n} / L_{s}=0.111$ and $\beta H_{L s}=0.925$ corresponding to the streamwise velocity perturbation at $x_{\text {out }} / L_{S}=0.444$ shown in Fig. 6.

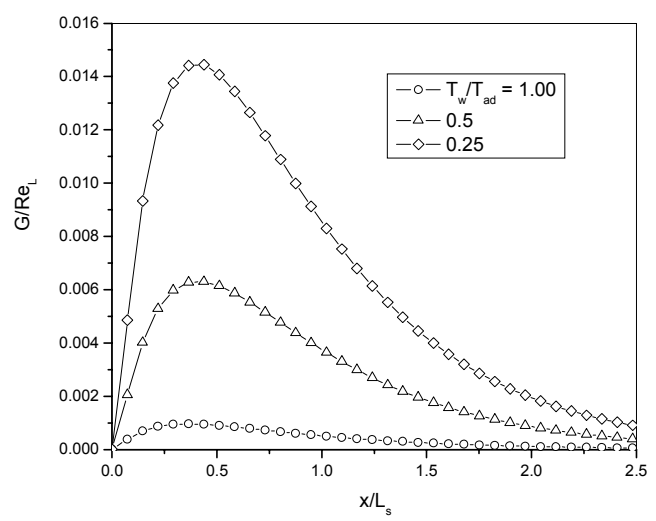

Figure 8. Effect of the temperature factor on energy growth at the experimental conditions of Ref. 13.

There is a possibility of enhancing the transient growth mechanism by means of wall cooling. The effect of wall cooling was investigated by Tumin and Reshotko $^{9}$ within the scope of a parallel flow approximation. In order to estimate possible increases of the energy ratio on a cold wall at a high favorable pressure gradient, we utilize the method of Ref. 9 for a compressible flow with local Mach number 0.5 and Hartree parameter 0.353 . The results are shown in Fig. 8. One can see that cooling of the wall might provide a tenfold increase in the energy ratio.

\section{Summary}

The results for the transient growth phenomenon within the scope of the linearized boundary-layer equations in the presence of a streamwise pressure gradient are consistent with previous results obtained within the scope of the parallel flow approximation and linearized Navier-Stokes equations. ${ }^{9}$ A favorable pressure gradient decreases the non-modal growth while an unfavorable pressure gradient leads to an increase of the amplification.

The example of a Falkner-Skan flow with a Hartree parameter $\beta_{H}=0.353$ corresponds to experimental data $^{13}$ and simulates the flow over a low-pressure turbine airfoil upstream of the separation point. At this pressure gradient, the transient growth mechanism is suppressed, and the energy amplification at low Reynolds number has a small value. The theory of the transient growth mechanism predicts that it is possible to enhance the energy growth by means of wall cooling. The example within the scope of the parallel flow theory ${ }^{9}$ demonstrates that cooling of the wall might provide a tenfold increase in the energy ratio. Future experiments on boundary layer tripping accompanied by wall cooling will contribute to our understanding of the bypass transition mechanism.

The method predicts that there is an optimal spacing between perturbers and their optimal location from the leading edge. The latter results can be utilized in future experiments with tripping of the boundary layer over the LPT airfoil. These type of experiment are planned to be carried out in facilities at NASA Glenn Research Center, ${ }^{14}$ at the US Naval Academy, ${ }^{13}$ and at the University of Notre Dame. ${ }^{15}$

Consideration of the optimal velocity perturbations in Fig. 7 indicates that they are distributed across the boundary layer. This means that an array of generators localized on the wall will not provide excitation of the optimal disturbances. Therefore, the question of realizability of the optimal disturbances arises. For example, one can solve the receptivity problem for an array of generators on the wall and find generator shapes (or other parameters), that provide velocity disturbance profiles closest to the optimal ones. Another option is to solve the receptivity problem for distributed generators upstream of the starting point, $x_{i n}$, and to find a generators distribution, that leads to the optimal disturbances. The next option is to design a disturbance generator that directly affects the flow inside the boundary layer instead of perturbing the near-wall region only. For example, it might be a focused laser beam projected from the wall, to where it could be delivered by a fiber-optic system. ${ }^{16}$ These fundamental issues should be addressed in future research programs on the application of bypass transition mechanisms to separation flow control at low Reynolds numbers. 


\section{Appendix}

For purpose of consistency of the formulation, we repeat the main features of the numerical scheme described in Ref. 5. Matrices $\mathbf{A}, \mathbf{B}_{0}, \mathbf{B}_{1}$, and $\mathbf{B}_{2}$ in Eq. (7) are as follows:

$$
\begin{gathered}
\mathbf{B}_{0}=\left(\begin{array}{cccc}
0 & 0 & -\beta & 0 \\
-\beta^{2} & -U_{y} & 0 & 0 \\
0 & -2 V_{y}-\beta^{2} & -\beta V & 0 \\
0 & 0 & -V_{y}-\beta^{2} & \beta
\end{array}\right) \\
\mathbf{B}_{1}=\left(\begin{array}{cccc}
0 & -1 & 0 & 0 \\
-V & 0 & 0 & 0 \\
0 & -2 V & 0 & -1 \\
0 & 0 & -V & 0
\end{array}\right) ; \mathbf{B}_{2}=\left(\begin{array}{cccc}
0 & 0 & 0 & 0 \\
1 & 0 & 0 & 0 \\
0 & 1 & 0 & 0 \\
0 & 0 & 1 & 0
\end{array}\right) \\
\mathbf{A}=\left(\begin{array}{cccc}
1 & 0 & 0 & 0 \\
U & 0 & 0 & 0 \\
V & U & 0 & 0 \\
0 & 0 & U & 0
\end{array}\right)
\end{gathered}
$$

The scheme utilized for Eq. (7) in the streamwise direction is

$$
\begin{gathered}
(\mathbf{A f})^{1}-(\mathbf{A f})^{0}= \\
\Delta x\left[\left(\mathbf{B}_{0} f\right)^{1}+\left(\mathbf{B}_{1} f_{y}\right)^{1}+\left(\mathbf{B}_{2} f_{y y}\right)^{1}\right] \\
\frac{3}{2}(\mathbf{A f})^{n+1}-2(\mathbf{A f})^{n}+\frac{1}{2}(\mathbf{A f})^{n-1}= \\
\Delta x\left[\left(\mathbf{B}_{0} f\right)^{n+1}+\left(\mathbf{B}_{1} f_{y}\right)^{n+1}+\left(\mathbf{B}_{2} f_{y y}\right)^{n+1}\right], n \geq 1
\end{gathered}
$$

where $n$ stands for the step number along the coordinate $x$. At each streamwise position, the onedimensional boundary-value problem is solved using a spectral collocation method based on Chebyshev polynomials. Usually, we used 100 intervals along the coordinate $x$ and 100 Chebyshev polynomials for the solution approximation.

To find the optimal perturbations corresponding to the maximum of the energy ratio in $(9 c)$, the forward solution of Eq. (7) is accompanied by the backward solution of the adjoint problem. ${ }^{5,6}$ In the present work, the adjoint system was discretized, i.e., the discretized adjoint equations were employed. Another approach is to utilize the adjoint form of the discretized forward equations (see discussion in Ref. 5). An arrangement of the iterations is described elsewhere. ${ }^{5,6}$ Usually, 2 to 3 iterations were enough to achieve convergence at the 0.1 percent level. 


\section{$\underline{\text { References }}$}

1. Ellingsen, T., and Palm, E., "Stability of Linear Flow," Phys. Fluids, Vol. 18, 1975, pp. 487-488.

2. Landahl, M. T. "A Note on an Algebraic Instability of Inviscid Parallel Shear Flows," J. Fluid Mech., Vol. 98, 1980, pp. 243-251.

3. Reshotko, E., "Transient Growth: A Factor in Bypass Transition," Phys. Fluids, Vol. 13, 2001, pp. 1067-1075.

4. Schmid, P.J., and Hennigson, D.S., Stability and Transition in Shear Flows, Springer, New York, 2001.

5. Andersson, P., Berggren, M., and Henningson, D., "Optimal Disturbances and Bypass Transition in Boundary Layers," Phys. Fluids, Vol. 11, 1999, pp. 134-150.

6. Luchini, P., "Reynolds Number Independent Instability of the Boundary Layer Over a Flat Surface, Part 2: Optimal Perturbations," J. Fluid Mech., Vol. 404, 2000, pp. 289-309.

7. Reshotko, E., and Tumin, A., "The Blunt Body Paradox - A Case for Transient Growth," Laminar-Turbulent Transition, edited by H. F. Fasel and W. S. Saric, Springer, New York, 2000, pp. 403-408.

8. Reshotko, E., and Tumin, A., "Spatial Theory of Optimal Disturbances in a Circular Pipe Flow," Physics of Fluids, Vol. 13, 2001, pp. 991-996.

9. Tumin, A., and Reshotko, E., "Spatial Theory of Optimal Disturbances in Boundary Layers," Physics of Fluids, Vol. 13, 2001, pp. 2097-2104.
10. Corbett, P., and Bottaro, A., "Optimal Perturbations for Boundary Layers Subjected to Stream-Wise Pressure Gradient," Phys. Fluids, Vol. 12, 2000, pp. 120-130.

11. Tumin, A., "A Model of Spatial Algebraic Growth in a Boundary Layer Subjected to a Streamwise Pressure Gradient," Phys. Fluids, Vol. 13, 2001, pp. 1521-1523.

12. Reshotko, E., and A. Tumin, "Investigation of the Role of Transient Growth in RoughnessInduced Transition," AIAA Paper No. 20022850, June 2002.

13. Volino, R.J., "Separated Flow Transition Under Simulated Low-Pressure Turbine Airfoil Conditions: Part 1 - Mean Flow and Turbulence Statistics," Proceedings of ASME TURBO EXPO 2002 Conference, Paper GT-2002-30236.

14. Volino, R.J., and Hultgren, L.S., "Measurements in Separated and Transitional Boundary Layers Under Low-Pressure Turbine Airfoil Conditions," Proceedings of ASME TURBO EXPO 2000 Conference, Paper 2000-GT-0260.

15. Huang, J., Corke, T.C., Thomas, F.O., "Separation Control Over Low Pressure Turbine Blades," Bulletin of the American Physical Society, Vol. 47, No. 10, Nov. 2002, p. 167.

16. Enikov, E., Private communication, University of Arizona, Tucson, 2002. 


\begin{tabular}{|c|c|c|}
\hline \multicolumn{2}{|c|}{ REPORT DOCUMENTATION PAGE } & $\begin{array}{l}\text { Form Approved } \\
\text { OMB No. 0704-0188 }\end{array}$ \\
\hline \multicolumn{3}{|c|}{$\begin{array}{l}\text { Public reporting burden for this collection of information is estimated to average } 1 \text { hour per response, including the time for reviewing instructions, searching existing data sources, } \\
\text { gathering and maintaining the data needed, and completing and reviewing the collection of information. Send comments regarding this burden estimate or any other aspect of this } \\
\text { collection of information, including suggestions for reducing this burden, to Washington Headquarters Services, Directorate for Information Operations and Reports, } 1215 \text { Jefferson } \\
\text { Davis Highway, Suite 1204, Arlington, VA 22202-4302, and to the Office of Management and Budget, Paperwork Reduction Project (0704-0188), Washington, DC 20503. }\end{array}$} \\
\hline 1. AGENCY USE ONLY (Leave blank) & \begin{tabular}{|c|c|} 
2. REPORT DATE & 3. \\
May 2003 &
\end{tabular} & $\begin{array}{l}\text { ID DATES COVERED } \\
\text { echnical Memorandum }\end{array}$ \\
\hline \multicolumn{2}{|c|}{$\begin{array}{l}\text { 4. TITLE AND SUBTITLE } \\
\text { Optimal Disturbances in Boundary Layers Subject to Streamwise } \\
\text { Pressure Gradient }\end{array}$} & \multirow{2}{*}{$\begin{array}{l}\text { 5. FUNDING NUMBERS } \\
\text { WBS-22-274-00-206 }\end{array}$} \\
\hline \multicolumn{2}{|c|}{$\begin{array}{l}\text { 6. AUTHOR(S) } \\
\text { Anatoli Tumin and David E. Ashpis }\end{array}$} & \\
\hline $\begin{array}{l}\text { 9. SPONSORING/MONITORING AGEI } \\
\text { National Aeronautics and } \mathrm{Sp} \\
\text { Washington, DC } 20546-00\end{array}$ & $\begin{array}{l}\text { NAME(S) AND ADDRESS(ES) } \\
\text { Administration }\end{array}$ & $\begin{array}{l}\text { 10. SPONSORING/MONITORING } \\
\text { AGENCY REPORT NUMBER } \\
\text { NASA TM-2003-212288 } \\
\text { AIAA-2003-4242 }\end{array}$ \\
\hline
\end{tabular}

\section{SUPPLEMENTARY NOTES}

Prepared for the 16th Computational Fluid Dynamics Conference and the 33rd Fluid Dynamics Conference and Exhibit sponsored by the American Institute of Aeronautics and Astronautics, Orlando, Florida, June 23-26, 2003. Anatoli Tumin, University of Arizona, Tucson, Arizona 85721; David E. Ashpis, NASA Glenn Research Center. Responsible person, David E. Ashpis, organization code 5820, 216-433-8317.

12a. DISTRIBUTION/AVAILABILITY STATEMENT

12b. DISTRIBUTION CODE

Unclassified - Unlimited

Subject Categories: 02, 07, and 34

Distribution: Nonstandard

Available electronically at http://gltrs.grc.nasa.gov

This publication is available from the NASA Center for AeroSpace Information, 301-621-0390.

13. ABSTRACT (Maximum 200 words)

An analysis of the non-modal growth of perturbations in a boundary layer in the presence of a streamwise pressure gradient is presented. The analysis is based on PSE equations for an incompressible fluid. Examples with FalknerSkan profiles indicate that a favorable pressure gradient decreases the non-modal growth while an unfavorable pressure gradient leads to an increase of the amplification. It is suggested that the transient growth mechanism be utilized to choose optimal parameters of tripping elements on a low-pressure turbine (LPT) airfoil. As an example, a boundary-layer flow with a streamwise pressure gradient corresponding to the pressure distribution over a LPT airfoil is considered. It is shown that there is an optimal spacing of the tripping elements and that the transient growth effect depends on the starting point. The amplification is found to be small at the LPT's very low Reynolds numbers, but there is a possibility to enhance the transient energy growth by means of wall cooling.

\begin{tabular}{|c|c|c|}
\hline \multicolumn{3}{|l|}{$\begin{array}{l}\text { 14. SUBJECT TERMS } \\
\text { Hydrodynamic st } \\
\text { Turbomachinery; }\end{array}$} \\
\hline $\begin{array}{l}\text { 17. SECURITY CLASSIFICATION } \\
\text { OF REPORT } \\
\text { Unclassified }\end{array}$ & $\begin{array}{l}\text { 18. SECURITY CLASSIFICATION } \\
\text { OF THIS PAGE } \\
\text { Unclassified }\end{array}$ & $\begin{array}{l}\text { 19. SECURITY CLASSIFICATION } \\
\text { OF ABSTRACT } \\
\text { Unclassified }\end{array}$ \\
\hline Unclassified & Unclassified & Unclassified \\
\hline
\end{tabular}

NSN 7540-01-280-5500

15. NUMBER OF PAGES

16. PRICE CODE

20. LIMITATION OF ABSTRACT

Standard Form 298 (Rev. 2-89)

Prescribed by ANSI Std. Z39-18 298-102 